\title{
Congenital Lung Malformation
}

National Cancer Institute

\section{Source}

National Cancer Institute. Congenital Lung Malformation. NCI Thesaurus. Code C98882.

A malformation in the lung that is present at birth. Representative examples include pulmonary hypoplasia, pulmonary agenesis, congenital lobar emphysema, and alveolar capillary dysplasia. 